\title{
ANALISIS HUBUNGAN SERVICE RECOVERY TERHADAP COMPLAINING BEHAVIOR DAN DAMPAKNYA TERHADAP BRAND SWITCHING
}

\author{
Dian Tauriana $^{1}$; $_{\text {Christine }}{ }^{2}$ \\ 1,2 Jurusan Manajemen, Fakultas Ekonomi dan Bisnis, Bina Nusantara University \\ Jln. K.H. Syahdan No. 9, Kemanggisan, Palmerah, Jakarta Barat 11480 \\ dtauriana@binus.edu
}

\begin{abstract}
PT Bank OCBC NISP Tbk officially became a commercial bank in 1967, foreign exchange bank in 1990, and listed as a public company in Indonesia Stock Exchange in 1994. The purpose of this research is to identify the correlation and variables influences of service recovery, complaining behaviour, and brand switching; and also to give suggestion of extensive complaint handling so the customers of PT Bank OCBC NISP Tbk are more loyal. The analysis method is SPSS 16.00 program, simple correlation, and path analysis. Data collecting technique is questionnaire, as the amount of respondents (customers) are 100. The result of this research is there is relation and influences among service recovery, complaining behaviour, and brand switching variables.
\end{abstract}

Keywords: service recovery, complaining behaviour, brand switching

\begin{abstract}
ABSTRAK
PT Bank OCBC NISP Tbk resmi menjadi bank komersial pada tahun 1967, bank devisa pada tahun 1990 dan menjadi perusahaan publik di Bursa Efek Indonesia pada tahun 1994. Tujuan penelitian adalah untuk mengetahui hubungan dan pengaruh variabel service recovery, complaining behavior, dan brand switching, serta memberikan usulan rekomendasi peningkatan penanganan keluhan yang lebih baik kepada perusahaan sehingga nasabah PT Bank OCBC NISP Tbk menjadi loyal. Metode analisis yang digunakan adalah menggunakan Program SPSS 16.00, korelasi sederhana, dan analisis jalur. Teknik pengumpulan data yang digunakan dalam penelitian ini adalah kuesioner. Jumlah nasabah yang diteliti adalah sebanyak 100 orang nasabah. Hasil yang dicapai dalam penelitian ini adalah adanya hubungan dan pengaruh antara variabel service recovery, complaining behavior, dan brand switching.
\end{abstract}

Kata kunci: service recovery, complaining behavior, brand switching 


\section{PENDAHULUAN}

\section{Latar Belakang}

Perbankan adalah salah satu industri jasa yang memegang peranan penting dalam bisnis. Usaha perbankan memberikan layanan kepada nasabahnya, mempertahankan nasabahnya untuk tetap setia menggunakan layanan jasanya. Loyalitas nasabah menunjukkan kepuasan nasabah. Semakin loyal seorang nasabah, semakin besar laba yang diperoleh perusahaan dari nasabah. Loyalitas nasabah menguntungkan bagi perusahaan. Service Recovery (Zemke \& Bell dalam Lewis \& Spyrakopoulos, 2001) merupakan suatu hasil pemikiran, rencana, dan proses untuk menembus kekecewaan pelanggan menjadi puas terhadap organisasi setelah pelayanan yang diberikan mengalami masalah (kegagalan). Complaining Behavior (Lovelock \& Wirtz, 2007) adalah tindakan konsumen yang berbeda-beda ketika mereka merasa tidak puas dengan suatu pembelian atau layanan. Brand Switching adalah perpindahan merek yang digunakan pelanggan untuk setiap waktu penggunaan.

Masalah yang sering sekali timbul di PT Bank OCBC NISP Tbk. adalah nasabah kurang mendapatkan pelayanan yang baik, seperti nasabah melakukan transaksi isi pulsa melalui mesin ATM, tabungan nasabah dipotong sebanyak transaksi yang dilakukan, tetapi pulsa tidak masuk ke kartu telepon nasabah. Keluhan nasabah juga berupa waktu nunggu penangganan yang lama sehingga nasabah merasa layanan di OCBC NISP kurang efesien, karyawan yang kurang mengerti tentang penggunan layanan sehingga tidak dapat menjelaskan lebih detail kepada nasabah. Tentunya keluhan yang disampaikan nasabah akan memberikan tanggapan negatif dan tidak baik untuk brand image dari bank tersebut, nasabah dapat melakukan tindakan negative word of mouth, melakukan tindakan legal, kemudian jumlah nasabah yang ada juga dapat berkurang karena nasabah berpindah ke bank lain yang lebih baik pelayanannya.

Mengacu pada latar belakang yang telah disampaikan, maka masalah yang dapat diidentifikasikan adalah sebagai berikut: (1) apakah ada hubungan service recovery terhadap complaining behavior; (2) apakah ada hubungan service recovery terhadap brand switching; (3) apakah ada pengaruh service recovery terhadap complaining behavior dan dampaknya terhadap brand switching. Sementara itu, tujuan penelitian ini adalah untuk: (1) mengetahui hubungan service recovery terhadap complaining behavior (T-1); (2) mengetahui hubungan service recovery terhadap brand switching (T-2); (3) mengetahui pengaruh service recovery terhadap complaining behavior dan dampaknya terhadap brand switching (T- 3). Service Recovery merupakan tindakan, pemikiran, rencana, dan proses untuk memperbaiki pelayanan bila terjadi kesalahan atau kekecewaan pelanggan dengan menebus kesalahan atau kekecewaan, sehingga pelanggan menjadi puas.Berdasarkan hasil beberapa observasi terhadap perusahaan-perusahaan jasa yang unggul, (Hendroyono, N.D.) merangkum hal-hal yang banyak diterapkan untuk menangani service recovery, yaitu: (1) melakukan aktivitas rekrutmen, penempatan, pelatihan, dan promosi yang mengarah pada keunggulan service recovery secara keseluruhan; (2) secara aktif mengumpulkan atau menampung keluhan pelanggan yang dipandang sebagai peluang dan penyempurnaan proses; (3) mengukur biaya primer dan sekunder dari pelanggan yang tidak puas, lalu melakukan penyesuaian investasi terhadap tingkat biaya tersebut; (4) memberdayakan karyawan lini depan untuk mengambil tindakan tepat dalam rangka service recovery; (5) mengembangkan jalur komunikasi yang singkat antara pelanggan dan manajer; (6) memberikan penghargaan kepada setiap karyawan yang menerima dan memecahkan masalah keluhan pelanggan, serta memperbaiki sumber-sumber masalahnya; (7) memasukkan keunggulan pelayanan dan recovery sebagai bagian dari strategi bisnis perusahaan; (8) komitmen manajer puncak terhadap dua hal utama, yaitu melakukan segala sesuatu secara benar sejak awal dan mengembangkan program service recovery yang efektif. 
Menurut Varki \& Ashley (2009), pelanggan yang setia lebih cenderung mengeluh langsung ke perusahaan, mereka mempunyai kemungkinan kecil untuk terlibat dalam perkataan negatif sebagai tanggapan atas kegagalan layanan.Juga, pelanggan setia mengekspresikan kepuasan yang lebih besar dengan upaya pemulihan layanan dibandingkan dengan pelanggan yang kurang setia ketika ganti rugi yang ditawarkan.Hal ini menunjukkan bahwa pelanggan yang mengeluh dapat menjadi pelanggan perusahaan yang paling setia dan pelanggan seperti ini berpotensi lebih responsif terhadap layanan upaya pemulihan.

Namun, tidak menanggani keluhan mereka dapat mengakibatkan hilangnya setia seseorang (pelanggan terbaik). Oleh karena itu, manajer perlu serius mempertimbangkan untuk melengkapi program loyalitas yang ada melalui sistem manajemen keluhan resmi. Sistem manajemen keluhan merupakan garis pertahanan terbaik dalam mempertahankan pelanggan yang sudah ada.

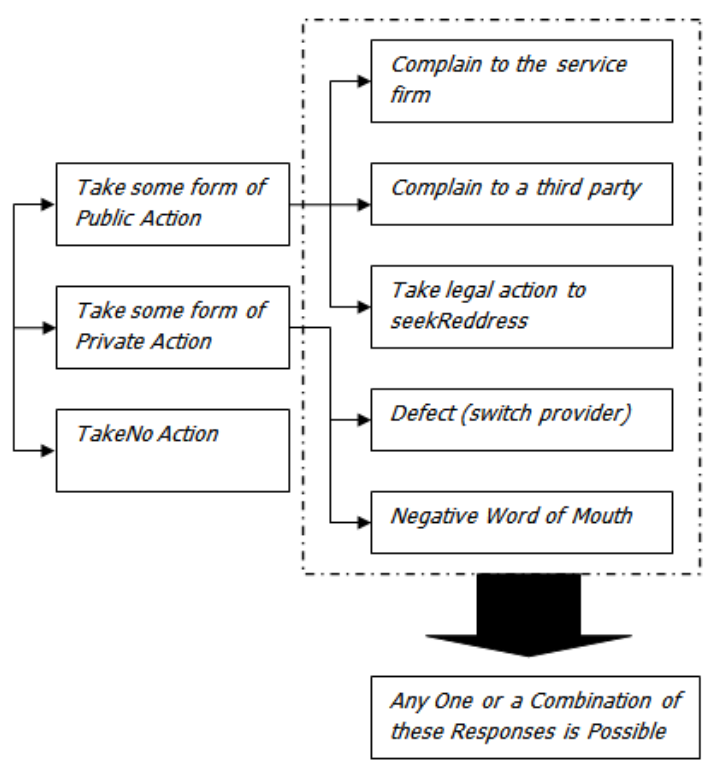

Gambar 1 Sistem manajemen keluhan

Para peneliti mengidentifikasi lima perilaku keluhan secara umum (Artikel Manajemen, 2008), yaitu: (1) menghadapi pengecer dengan cara tertentu; (2) menghindari pengecer yang sama dan membujuk teman- teman / keluarganya untuk menjauhi pengecer yang sama; (3) mengambil tindakan terbuka yang melibatkan pihak ketiga (misalnya, melancarkan tindakan yang resmi untuk mendapatkan ganti rugi); (4) memboikot perusahaan atau organisasi; (5) menciptakan organisasi alternatif untuk menyediakan barang dan jasa.

Ada tipe-tipe orang yang mengeluh (complainers) yang dijelaskan oleh Leland \& Bailey (2008) yang masih berkorelasi dengan Lovelock \& Wirtz (2007), yaitu: (1) the go for the throaters; (2) the quiet as the mousers; (3) the high roller; (4) the whiners; (5) the tricksters. Mengapa pelanggan melakukan complaint? Ada beberapa alasan, seperti mendapatkan ganti rugi atau kompensasi, melampiaskan kemarahan mereka, bantuan untuk meningkatkan layanan, serta untuk alasan kepentingan orang lain. Lalu, mengapa pelanggan yang tidak puas tidak melakukan complaint? Bisa jadi karena tidak mau direpotkan dengan mengisi angket, menulis surat complaint, ataupun menelpon; banyak pelanggan yang melihat bahwa dari complaint yang diajukan tidak mendapatkan respon dari pihak penyedia layanan; tidak adanya sarana untuk menyampaikan complaint; sebagian orang menganggap bahwa complaint merupakan suatu tindakan yang kurang baik; perilaku complaint juga dapat dipengaruhi oleh persepsi peran dan norma sosial. 
Menurut Peter dan Olson (2000), perpindahan merek (brand switching) adalah pola pembelian yang dikarakteristikkan dengan perubahan atau pergantian dari satu merek ke merek yang lain. Perilaku perpindahan merek dapat terjadi dikarenakan beragamnya produk yang ada dipasaran sehingga menyebabkan adanya perilaku memilih produk sesuai dengan kebutuhan atau karena terjadi masalah dengan produk yang sudah dibeli maka konsumen kemudian beralih ke merek lain. Brand switching juga dapat terjadi ketika konsumen merasa kecewa dengan produk yang pernah dia beli berdasarkan pengalamannya, konsumen merasa tidak puas dan kemudian menggunakan merek lain sebagai produknya. Perusahaan akan mengalami kerugian apabila konsumen melakukan peralihan merek ke merek lain. Perilaku brand switching ini dipengaruhi oleh beberapa faktor (Shi, Cheung \& Prendergast, 2005). Faktor-faktor tersebut antara lain: (1) price atau pembentukan harga; (2) sales promotion atau promosi penjualan; (3) munculnya produk-produk baru (attraction by competitors); (4) kualitas; (5) distribusi.

Sekali kegagalan pelayanan terjadi, itu menjadi penting dilakukannya pelayanan pemulihan, didefinisikan sebagai tindakan yang dilakukan oleh penyedia layanan untuk mencari ketidakpuasan pelanggan dan sebagai respon terhadap kualitas layanan yang buruk secara efektif dilakukan untuk mengurangi kerusakan pada hubungan dan untuk menenangkan pelanggan yang tidak puas. Hal ini juga telah menyarankan bahwa pemulihan pelayanan yang efektiftelah menyebabkan kepuasan yang lebih tinggi dibandingkan dengan layanan yang telah benar dilakukan pada pertama kali. Fenomena ini paradoks layanan pemulihan juga (Kau \& Loh, 2006).

Konsumen yang merasa tidak puas (melakukan complaint) dapat melakukan tindakan peralihan merek (brand switching) demi tercapainya tingkat kepuasan yang mereka dambakan. Konsumen yang melakukan peralihan merek mengharapkan merek lain itu dapat memberikan kepuasan kepadanya melalui produk maupun jasa. (Kau \& Loh, 2006). Kegagalan untuk melakukan layanan pasti menyebabkan ketidakpuasan pelanggan. Kerusakan hubungan dengan pelanggan dapat memberikan kontribusi kenaikan pelanggan keluhan, komunikasi erkataan buruk dari mulut ke mulut dan pembelotan. Service recovery bukan hanya sekedar penanganan terhadap keluhan dan interaksi antara penyedia layanan dan pelanggan. Sebuah sistem service recovery yang baik juga mendeteksi dan memecahkan masalah, mencegah kekecewaan dan menanggapi keluhan. (Abaca, Mendez, Rindfleish, Pearson \& Epworth, 2005). Menurut Kau \& Loh (2006), ketidakpuasan konsumen dapat berakibat buruk terhadap perusahaan karena bisa mengakibatkan hilangnya sebagian pangsa pasar yang otomatis akan mengakibatkan menurunnya profit perusahaan. Konsumen yang merasa tidak puas dapat melakukan tindakan beralih merek (brandswitching) demi tercapainya tingkat kepuasan yang mereka dambakan.

\section{METODE PENELITIAN}

\section{Kerangka Pemikiran}

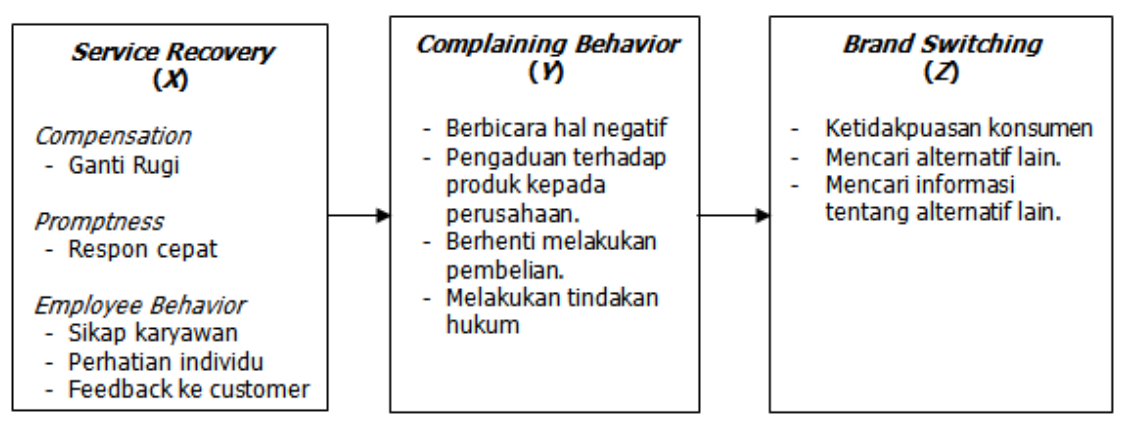


Tabel 1 Kerangka Pemikiran

\begin{tabular}{ccccc}
\hline $\begin{array}{c}\text { Tujuan } \\
\text { Penelitian }\end{array}$ & Jenis Penelitian & $\begin{array}{c}\text { Metode } \\
\text { Penelitian }\end{array}$ & Unit Analisis & Time Horizon \\
\hline $\mathrm{T}-1$ & Deskriptif & Kuesioner & Individu - nasabah & Cross Sectional \\
$\mathrm{T}-2$ & Deskriptif & Kuesioner & Individu - nasabah & Cross Sectional \\
$\mathrm{T}-3$ & Deskriptif - Asosiatif & Kuesioner & Individu - nasabah & Cross sectional \\
\hline
\end{tabular}

\section{Operasional Variabel Penelitian}

Tabel 2 Operasional Variabel Penelitian

\begin{tabular}{|c|c|c|c|c|c|}
\hline Variabel & Dimensi & Definisi & Indikator & Ukuran & Skala \\
\hline \multirow[t]{3}{*}{$\begin{array}{l}\text { Service } \\
\text { Recovery } \\
(x)\end{array}$} & $\begin{array}{l}\text { Compensantion } \\
\text { (Kompensasi/ } \\
\text { Balasan Jasa) }\end{array}$ & $\begin{array}{l}\text { Imbalan yang diterima } \\
\text { atas hasil kerja pada } \\
\text { organisasi. }\end{array}$ & - Ganti Rugi & \multirow[b]{3}{*}{ Ordinal } & \multirow[b]{3}{*}{ Likert } \\
\hline & $\begin{array}{l}\text { Promptness } \\
\text { (Kecepatan) }\end{array}$ & $\begin{array}{l}\text { Kecepatan atau } \\
\text { ketepatan waktu }\end{array}$ & $\begin{array}{l}\text { - Respon cepat penanganan } \\
\text { keluhan }\end{array}$ & & \\
\hline & $\begin{array}{l}\text { Employee } \\
\text { Behaviour } \\
\text { (Perilaku } \\
\text { karyawan) }\end{array}$ & $\begin{array}{l}\text { Tindakan karyawan } \\
\text { dalam melakukan } \\
\text { sesuatu. }\end{array}$ & $\begin{array}{l}\text { - Sikap karyawan } \\
\text { - Perhatian individu } \\
\text { - Feedback ke customer }\end{array}$ & & \\
\hline $\begin{array}{l}\text { Perilaku Keluhan } \\
\text { Konsumen } \\
(Y)\end{array}$ & - & $\begin{array}{l}\text { Bentuk ketidakpuasan } \\
\text { atau kekecewaan } \\
\text { konsumen terhadap } \\
\text { produk } \\
\text { barang atau jasa. }\end{array}$ & $\begin{array}{l}\text { - } \text { Berbicara hal negative } \\
\text { - Pengaduan terhadap produk } \\
\text { kepada perusahaan. } \\
\text { - Berhenti melakukan } \\
\text { pembelian. } \\
\text { - Melakukan tindakan } \\
\text { hukum. }\end{array}$ & Ordinal & Likert \\
\hline $\begin{array}{l}\text { Brand Switching } \\
\text { (Z) }\end{array}$ & - & $\begin{array}{l}\text { Peralihan merek dari } \\
\text { merek yang satu ke } \\
\text { merek yang lain. }\end{array}$ & $\begin{array}{ll}\text { - } & \text { Ketidakpuasan konsumen } \\
\text { - } & \text { Mencari alternatif lain. } \\
\text { - } & \text { Mencari informasi tentang } \\
& \text { alternatif lain. }\end{array}$ & Ordinal & Likert \\
\hline
\end{tabular}

\section{Jenis dan Sumber Data dalam Penelitian}

Tabel 3 Jenis dan Sumber Data Dalam Penelitian

\begin{tabular}{llc}
\multicolumn{1}{c}{ Data } & \multicolumn{1}{c}{ Jenis Data } & Sumber data \\
\hline $\begin{array}{l}\text { Jumlah nasabah PT.Bank } \\
\text { OCBC NISP Tbk. }\end{array}$ & Kualitatif & Primer - Kuesioner \\
$\begin{array}{l}\text { Jumlah nasabah PT. Bank } \\
\text { OCBC NISP.Tbk }\end{array}$ & Kualitatif & Primer - Kuesioner \\
Jumlah nasabah PT.Bank & Kualitatif & Primer - Kuesioner \\
OCBC NISP.Tbk & & \\
\hline
\end{tabular}

\section{Teknik Pengumpulan Data}

Teknik pengumpulan data dalam penelitian ini yaitu: (1) studi kepustakaan (library research); (2) studi lapangan (field research), yaitu wawancara (interview), pengamatan (observasi), serta kuesioner. 


\section{Teknik Pengambilan Sampel}

Teknik pengambilan sampel yang digunakan pada penelitian ini adalah probability sampling. Probability sampling adalah suatu metode pemilihan sampel, di mana setiap anggota populasi mempunyai peluang yang sama untuk dipilih menjadi anggota sampel (Umar, 2003).Teknik yang digunakan adalah simple probability sampling, yaitu pengambilan sampel anggota populasi secara acak, tanpa memperhatikan strata yang ada.Yang menjadi responden adalah nasabah di PT Bank OCBC NISP Tbk.

\section{Teknik Pengolahan Sampel}

$$
\begin{aligned}
& n=\frac{N}{N+d^{2}+1} \\
& n=\frac{300}{300 \cdot(0.1)^{2}+1}=75 \text { responden }
\end{aligned}
$$

Jadi jumlah minimal sampel penelitian ini adalah 75 responden. Menurut Sarwono (2007), sebaiknya untuk riset sebenarnya gunakan sampel minimal 100 untuk memperoleh hasil analisis yang signifikan dan lebih akurat. Oleh karena itu, dalam penelitian ini peneliti akan membagikan kuesioner kepada 100 nasabah di PT Bank OCBC NISP Tbk.

\section{Metode Analisis Data}

Tabel 4 Metode Analisis Data

\begin{tabular}{ccc}
\hline \multirow{2}{*}{ Tujuan Penelitian } & \multicolumn{2}{c}{ Metode Analisis } \\
& Jenis penelitian & Teknik analisis \\
\hline T-1 & Deskriptif & Korelasi Sederhana \\
T-2 & Deskriptif & Korelasi Sederhana \\
T-3 & Deskriptif - Asosiatif & Analisis Jalur \\
\hline
\end{tabular}

\section{HASIL DAN PEMBAHASAN}

\section{Analisis Korelasi Sederhana}

Tabel 5 Analisis korelasi sederhana

\begin{tabular}{ccc}
\hline Hubungan Antara & Korelasi & Sifat Hubungan \\
\hline$X$ terhadap $Y$ & 0,782 & Kuat, searah, dan signifikan \\
$X$ terhadap $Z$ & 0,767 & Kuat, searah, dan signifikan \\
\hline
\end{tabular}

\section{Analisis Jalur}

Tabel 6 Analisis jalur

\begin{tabular}{clccc}
\hline \multirow{2}{*}{$\begin{array}{c}\text { Pengaruh } \\
\text { Variabel }\end{array}$} & \multirow{2}{*}{ Koefisien Jalur } & \multicolumn{2}{c}{ Pengaruh } & \multirow{2}{*}{ Total } \\
\cline { 2 - 4 } & & Langsung & Tidak langsung & \\
\hline $\mathbf{X}-\mathbf{Y}$ & 0,782 & 0,782 & - & 0,782 \\
$\mathbf{X}-\mathbf{Z}$ & 0,203 & 0,203 & $=0,782 \times 0,705$ & 0,705431 \\
& & & $=0,55131$ & \\
Y-Z & 0,705 & 0,705 & - & 0,705 \\
\hline
\end{tabular}


Hubungan antara service recovery dengan complaining behavior sebesar 0,782, angka ini menunjukkan bahwa ada hubungan yang kuat antara service recovery dengan complaining behavior. Pengaruh service recovery terhadap complaining behavior sebesar $61,15 \%$ dan sisanya sebesar 38,85\% dipengaruhi oleh variabel lain diluar penelitian ini. Artinya kegagalan dalam melayani pelanggan menyebabkan ketidakpuasan pada pelanggan yang akan berakibat buruk bagi penyedialayanan. Kerusakan dalam hubungan dapat menyebabkan pelanggan mengeluh. Oleh karena itu sekali kegagalan pelayanan terjadi, penting untuk melakukan pemulihan pelayanan (Kau \& Loh, 2006). Service Recovery ini sendiri mencakup ganti rugi, respon cepat penanganan keluhan, sikap karyawan, perhatian individu, umpan balik ke customer. Hal ini berarti jika PT Bank OCBC NISP Tbk ingin mengurangi tingkat keluhan dari nasabahnya maka salah satu faktor yang dapat dipilih adalah meningkatkan perhatian individu ke nasabah sehingga PT Bank OCBC NISP Tbk dapat memberikan respon yang lebih cepat (kurang dari 2X24jam).

Service Recovery secara langsung mempengaruhi Brand Switching sebesar 4,12\% dan sisanya sebesar 95,88\% dipengaruhi oleh variabel lain diluar penelitian ini. service recovery dengan brand switching mempunyai hubungan yang kuat sebesar 0,767 (76,7\%). Artinya walaupun telah dilakukan penanganan layanan keluhan, nasabah akan tetap melakukan perpindahan bank apabila mereka tertarik dengan hal-hal lain. Faktor-faktor yang mempengaruhi perpindahan merek antara lain: harga, promosi, munculnya produk baru, kualitas, distribusi (Shi, Cheung \& Prendergast, 2005). Upaya yang dapat dilakukan oleh PT Bank OCBC NISP Tbk yaitu mempertahankan bunga banknya sama tinggi dengan bank-bank yang lain sehingga nasabah PT Bank OCBC NISP Tbk tidak pindah ke bank lain karena bank lain memberikan bunga yang lebih tinggi.

Pengaruh complaining behavior terhadap brand switching sebesar 49,7\% dan sisanya sebesar 50,3\% dipengaruhi oleh variabel lain diluar penelitian ini. Hal ini menunjukkan bahwa ketidakpuasan konsumen muncul karena pengharapan konsumen tidak sama atau lebih tinggi daripada kinerja yang diterima. Dengan demikian semakin tinggi ketidakpuasan konsumen yang membuat konsumen mengeluh maka semakin tinggi keputusan perpindahan merek (Junaidi \& Dharmmesta, 2002). Upaya untuk meminimal tingkat keluhan dan tingkat perpindahan nasabah ke bank lain dapat dilakukan dengan meningkatkan kinerja PT Bank OCBC NISP Tbk, seperti: melakukan penambahan produk perbankan dan pembaharuan sarana yang digunakan untuk aktivitas perbankan di PT Bank OCBC NISP Tbk.

\section{PENUTUP}

\section{Simpulan}

Service recovery mempunyai hubungan yang kuat terhadap complaining behavior. Pengaruh service recovery terhadap complaining behavior menunjukkan adanya kontribusi yang signifikan terhadap brand switching secara simultan. Pengaruh service recovery terhadap complaining behavior sebesar $61,15 \%$ dan sisanya sebesar $38,85 \%$ dipengaruhi oleh variabel lain di luar penelitian ini. Artinya kegagalan dalam melayani pelanggan menyebabkan ketidakpuasan pada pelanggan yang akan berakibat buruk bagi penyedia layanan. Kerusakan dalam hubungan dapat menyebabkan pelanggan mengeluh. Oleh karena itu sekali kegagalan pelayanan terjadi, penting untuk melakukan pemulihan pelayanan (Kau \& Loh, 2006). Melalui hasil data kuesioner yang didapat, apabila nasabah merasa tidak puas, maka nasabah akan berhenti melakukan layanan PT Bank OCBC NISP Tbk., ada juga yang menceritakan komentar negatif ke orang lain ketika mereka merasa tidak puas. 
Service recovery mempunyai hubungan yang kuat terhadap brand switching. Pengaruh service recovery menunjukkan adanya kontribusi yang signifikan terhadap brand switching secara simultan. Service recovery secara langsung mempengaruhi brand switching sebesar 4,12\% dan sisanya sebesar 95,88\% dipengaruhi oleh variabel lain di luar penelitian ini. Artinya walaupun telah dilakukan penanganan layanan atau keluhan, nasabah akan tetap melakukan perpindahan merek apabila mereka tertarik dengan hal-hal lain. Faktor-faktor yang mempengaruhi perpindahan merek antara lain: harga, promosi, munculnya produk baru, kualitas, distribusi (Shi, Cheung \& Prendergast, 2005). Melalui hasil data kuesioner yang didapat, keseluruhan nasabah PT Bank OCBC NISP Tbk. menyukai bunga yang tinggi, mereka akan mencari bank yang lain, apabila bank yang lain memberikan tingkat bunga yang lebih tinggi. Hubungan complaining behavior terhadap brand switching cukup kuat. Pengaruh complaining behavior terhadap brand switching sebesar 49,7\% dan sisanya sebesar 50,3\% dipengaruhi oleh variabel lain diluar penelitian ini. Hal ini menunjukkan bahwa ketidakpuasan konsumen muncul karena pengharapan konsumen tidak sama atau lebih tinggi daripada kinerja yang diterima. Dengan demikian semakin tinggi ketidakpuasan konsumen yang membuat konsumen mengeluh maka semakin tinggi keputusan perpindahan merek (Junaidi \& Dharmmesta, 2002).

\section{Saran}

Ada beberapa saran untuk perusahaan PT Bank OCBC NISP Tbk dan saran untuk penelitian selanjutnya. Saran-saran yang diberikan hasil penelitian ini yaitu: (1) sebaiknya PT Bank OCBC NISP Tbk meningkatkan suku bunganya sehingga nasabahnya tidak berpindah ke bank yang lain atau tetap mempertahankan bunga banknya seimbang dengan bank lain. Karena menurut hasil data kuesioner, nasabah PT Bank OCBC NISP Tbk akan berpindah ke bank yang lain apabila bunga yang ditawarkan bank lain lebih tinggi. (2) Ketatnya persaingan PT Bank OCBC NISP Tbk dengan bank-bank swasta yang lain, sehingga PT Bank OCBC NISP Tbk perlu memperbaiki pelayanan jasa dan menangani keluhan nasabah lebih cepat dari bank lain, dimana bank lain memberikan penangganan keluhan (kurang dari 2x24jam). (3) Karyawan PT Bank OCBC NISP Tbk dapat mempertahankan hubungan yang baik dengan nasabahnya secara individu dengan cara tetap bersikap ramah ke nasabah, memberikan update kondisi perekenomian dalam dan luar negeri. (4) PT Bank OCBC NISP Tbk dapat terus memberikan produk- produk baru yang memberikan keuntungan untuk nasabah, seperti deposito (keuntungan: bunga), reksa dana (keuntungan: nasabah mendapatkan untung dari kenaikan harga saham, obligasi, dan pasar uang).

\section{DAFTAR PUSTAKA}

Abaca, F. V., Mendez, J. R., Rindfleish, J., Pearson, D., \& Epworth, R. (2005). Assessing the antecedents of service recovery evaluation and their impact on repurchase behavior. Working Paper Series (WPS) No. 6.

Artikel Manajemen. (2008). Perilaku Keluhan Konsumen Part 1. Diakses dari http://artikelmanajemen.blogspot.com/2008/08/perilaku-keluhan-konsumen-part-1.html

Hendroyono, A. (N.D.). Mutu pelayanan kesehatan \& service recovery. Diunduh dari http://www.lrckesehatan.net/upload/mutu\%20pelayanan.pdf

Junaidi, S., \& Dharmmesta, B. S. (2002). Pengaruh ketidakpuasan konsumen, karakteristik kategori produk, dan kebutuhan mencari variasi terhadap keputusan perpindahan merek. Jurnal Ekonomi dan Bisnis Indonesia. Vol 17. No.1 hal 91-102. 
Kau, A. K., \& Loh, E. W. Y. (2006). The effects of service recovery on consumer satisfaction: a comparison between complaints and non-complaints. Singapore: National University of Singapore.

Leland, K., \& Bailey, K. (2008). Customer service in an instant: 60 ways to win customers and keep them coming back (in an instant). Franklin Lakes, New Jersey: Career Press.

Lovelock, C. H., \& Wirtz, J. (2007). Service marketing people, technology, strategy (6th ed.). New Jersey: Pearson Prentice Hall.

Lewis, B. R., \& Spyrakopoulos, S. (2001). Service failure and recovery in retail bank: the customer's perspective. International Journal of Bank Marketing, Vol. 19 hal 34-47.

Peter, J. P., \& Olson, J. C. (2000). Consumer behavior and marketing strategy . New York: Mc-Graw Hill.

Sarwono, J. (2007). Analisis jalur untuk riset bisnis dengan SPSS. Yogyakarta: ANDI.

Shi, Y. Z., Cheung, K. M., \& Prendergast, G. (2005). Behaviroual response to sales promotion tools: A Hong Kong study. International Journal of Advertising. Vol. 24, Iss. 4.

Umar, H. (2003). Metode riset bisnis. Jakarta: Gramedia Pustaka Utama.

Varki, S., \& Ashley, C. (2009) Loyalty and its influence on complaining behavior and service recovery satisfaction. Jurnal of Marketing , p21. 